\title{
The Farmers Market Metrics Project: A research brief on scalable data collection in the Minneapolis-St. Paul Metro
}

\author{
Hikaru Hanawa Peterson ${ }^{a} *$ and Joseph J. Nowak b \\ University of Minnesota Twin Cities
}

Submitted April 5, 2018 / Revised July 14 and October 20, 2018, and January 9 and January 23, 2019 /

Accepted March 5, 2019 / Published online June 16, 2019 / Article title corrected June 26, 2019

Citation: Peterson, H. H., \& Nowak, J. J. (2019). The Farmers Market Metrics Project: A research brief

on scalable data collection in the Minneapolis-St. Paul Metro. Journal of Agriculture, Food Systems, and

Community Development, 9(1), 69-74. https://doi.org/10.5304/jafscd.2019.091.011

Copyright (C 2019 by the Authors. Published by the Lyson Center for Civic Agriculture and Food Systems. Open access under CC-BY license.

\begin{abstract}
Maintaining funding for local and regional food system initiatives requires reliable data to demonstrate their impacts. Data that are specific to farmers markets in a localized context are not readily available. The Farmers Market Metrics Project is a three-way partnership between farmers markets, local government, and a university to elevate the capacity of the markets in the Minneapolis-St. Paul Metro region through regionally collected metrics to quantify their presence in the regional food system. In this research brief, we introduce the FM360 data collection method being developed by the project, which is scalable across geographic areas. Scalability is critical to making the data

\footnotetext{
a $*$ Corresponding author: Hikaru Hanawa Peterson, Professor, Department of Applied Economics, University of Minnesota Twin Cities; 1994 Buford Avenue; St. Paul, MN 55108 USA; hhp@umn.edu

b Joseph J. Nowak, Ph.D. student, Department of Forest Resources, University of Minnesota Twin Cities.
}

collection process adaptable and effective in cases involving multiple data sources and when flexibility is needed in defining the food system parameters to satisfy partners and prospective funders.

\section{Keywords}

Collaborative, Community-University Partnership, Farmers Markets, Market Managers, Metrics, Minneapolis-St. Paul, Primary Data Collection, Regional Food System, Vendors, Visitors

\section{Introduction}

Public, private, and nonprofit entities have increasingly championed local and regional food systems, as consumer interest in healthy foods and thriving local communities has grown. These local and regional initiatives are typically propelled by a series

\section{Funding Disclosures}

Grant funding from the U.S. Department of Agriculture Farmers Market Promotion Program and the Urban Sustainability Directors Network is gratefully acknowledged. 
of term-defined projects and initiatives funded by public, private, and nonprofit sources. Short-term funding, however, has the potential to discourage momentum, and funding opportunities for continued work are much more limited than those for new projects. Farmers markets, "the historical flagship of local food systems" (Brown \& Miller, 2008, p. 1296), face competition for the limited financial resources available for local and regional food systems, from various initiatives, old and new alike. Evaluations or impact assessments are effective ways to overcome such barriers to secure sustained funding, but such assessments require reliable metrics or data. In most cases, data that are specific to farmers markets in a localized context are not readily available and require primary data collection.

In major U.S. metropolitan regions, farmers markets share both vendors and patrons. The Minneapolis-St. Paul seven-county metro region (the MSP metro or the Twin Cities) is home to about 90 farmers markets. These markets vary in size, ownership, governance, and management structure. The oldest of the markets, the St. Paul Farmers Market, dates back to 1853. The largest of the markets, the Minneapolis Farmers Market on Lyndale Avenue, first opened in 1937. Many smaller markets have opened within the past decade, bringing fresh local produce directly to neighborhoods, public spaces, and even office buildings. Despite the apparent vibrancy, several farmers markets have seen a decline in support or patronage, as they compete with corporate retail outlets or food cooperatives touting similar offerings of fresh local foods and possibly with other farmers markets. When vendor and customer bases overlap, documenting the activities of one farmers market in isolation is not very meaningful. Demonstrating the combined activities of all markets within a region across multiple layers of jurisdictions is a challenge that no individual market can take on alone.

The MSP Metro Farmers Market Metrics Project emerged from the efforts of several farmers market managers who noticed a lack of basic data on farmers markets in the region. Partnerships with the City of Minneapolis and the University of Minnesota provided critical guidance, resources, and skills to capitalize on the impetus of the market managers. As such, the project developed a regional approach to food system metrics collection based on this unique, three-way partnership between farmers markets, local government, and university. In late 2018, it completed the second year of a three-year project funded by the U.S. Department of Agriculture (USDA) Farmers Market Promotion Program.

The primary goal of the Farmers Market Metrics Project is to elevate the capacity of farmers markets in the MSP Metro region to articulate their own value to the local food system. The project also aims to establish an efficient, effective, and scalable data collection method for measuring farmers market activities in a defined area. Scalability is important because geographic and political boundaries that shape the collective identities of farmers markets (e.g., neighborhood, city, or county) are nebulous and overlapping. Standardized metrics can be aggregated over given localities or regions to meet the needs of different audiences to effectively garner support for the markets. This research brief introduces FM360, which is the data collection approach we developed during the first years of the project, and demonstrates considerations in cases involving multiple data sources across administrative boundaries. We conclude with a discussion of factors contributing to the success of the project thus far, challenges ahead, and how the project may be useful to others.

\section{Literature Review}

The three main stakeholders of farmers markets are vendors, consumers, and managers. Studies that report the impacts or activities of farmers markets have generally collected primary data because secondary data are not readily available for their purposes, although few studies provide details about the data collection methods. Most numerous are studies based on data collected from visitors at farmers markets aimed at understanding their characteristics, preferences, and shopping behavior. Typically, visitors are intercepted at the market by surveyors based on an established sampling method (e.g., Sadler, Clark, \& Gilliland, 2013). Rapid Market Assessment (RMA; Lev, Brewer, \& Stephenson, 2008) was developed to help farmers markets obtain visitor metrics without elaborate 
survey work. They propose to count arriving visitors in 10- or 20-minute intervals and ask visitors to respond to a limited number of multiple-choice questions posted on easels using round stickers. These dot surveys have become familiar fixtures in farmers markets.

A few studies across the country have collected data from more than one market stakeholder group at multiple markets. Notable examples include those in Iowa (Varner \& Otto, 2008), Oklahoma (Henneberry, Whitacre, \& Agustini, 2009), South Carolina (Hughes \& Isengildina-Massa, 2015), Washington (Ostrom \& Donovan, 2013), Maine (Maine Federation of Farmers' Markets, 2017), and upstate New York (Schmit \& Gómez, 2011). Farmers' Markets Canada contracted a comprehensive national study to establish a benchmark in 2009 encompassing 508 farmers markets identified across the country (Experience Renewal Solutions, 2009). As methodological innovations besides RMA, self-assessment tools have been developed for markets to demonstrate their impacts. The Sticky Economic Evaluation Device (SEED) by Market Umbrella, an independent nonprofit organization, allows for markets to collect and store data through their online accounts and process data to generate detailed impact reports. The service is available to markets for free in exchange for giving Market Umbrella access and publishing rights to their data (Market Umbrella, 2012). The Farmers Market Coalition (FMC), a national advocacy organization in the U.S. for farmers markets, offers Farmers Market Metrics, an online system of data collection and reporting, which is available to markets for a fee (FMC, n.d.-b).

Specific guidance on how to implement an urban regional metric collection is limited. The Farmers Market Metrics Project contributes to the literature by exploring and refining ways to collect data from three stakeholder groups across the region. The project uses a scalable approach based on a three-way partnership between farmers markets, local government, and a university. We refer to the resulting data collection method as FM360.

\section{Methods}

The makeup of the project team is a unique aspect of the Farmers Market Metrics Project. As has been previously mentioned, the project is led by a three-way partnership that consists of market managers, local government staff, and academics. In the case of our project, the university represented on the team is the University of Minnesota, and the local government is the City of Minneapolis. Most of the earliest markets that participated in the project were from Minneapolis. While the project's leadership reflects this history, members of other communities are continuing to get more involved as the project expands.

The USDA defines farmers markets as "markets that feature two or more farm vendors selling agricultural products directly to customers at a common, recurrent physical location" (USDA Agricultural Marketing Service, n.d., para. 1). Thus, markets are defined by their physical location, even if multiple markets are referred to as a group and/or managed by the same entity or individual. The same market may operate on more than one day in a given week. The project also includes public markets with a single farm vendor selling agricultural products along with other nonfarm vendors. According to the USDA's National Farmers Market Directory, as of March 2018, there were 196 markets in Minnesota, 79 of which were within the MSP metro region. But the local market scene is larger and more dynamic than what is posted in the directory. The lists of markets maintained by county agencies and the City of Minneapolis showed there to be 87 markets in the MSP metro region, and the project team members were made aware of new markets opening and existing ones closing throughout the summer months. Thus, the scope of the Farmers Market Metrics Project-i.e., including all farmers markets in the MSP metro region - is both well-defined and constantly fluctuating.

The project team referenced the list of 37 metrics identified by the FMC (n.d.-a) to select the metrics of interest. Given the dearth of information, obtaining basic counts of total vendors and estimated total visitors and the total market sales were clear priorities. For the latter, the team did not feel comfortable with the FMC's recommended method to mandate or request vendors to submit anonymously completed slips at the end of the market day. Instead, the team decided to ask all 
vendors to identify their annual sales in the preceding market season by choosing in the survey the range of sales that would apply to them. This was augmented with an option for some selected vendors to provide weekly sales information over the market season in return for a stipend. The team felt it was critical to avoid imposing additional burdens on managers and vendors during the project implementation, in contrast to the self-assessment approach of Market Umbrella and FMC. Additionally, the team decided to avoid reliance on volunteers to ensure that metrics were collected in a unified manner across markets for consistency. ${ }^{1}$ Hence, the collection and entry of metrics were handled by a field crew that was trained and managed by the university researcher. The field crew collecting the customer data via dot surveys was coordinated and monitored by the university researcher and graduate assistant. The graduate assistant also distributed and collected the vendor surveys both at pre-season vendor meetings and at farmers markets throughout the entirety of the market season. The manager survey was administered online and designed to be completed for each market. Managers who oversaw multiple markets received a unique survey link for each market. The university researcher drafted and finalized instruments for each of the three surveys with input from the other team members. The university researcher also assumed the role of maintaining the metrics database.

For visitor metrics, the team applied the RMA (Lev et al., 2008) using dot surveys and visitor counting with a modification. By requiring fewer people to conduct the counts, the visitor count modification aims to make the metric more attainable for markets with fewer resources (Nowak, 2019). In addition to the four dot-survey questions, the field crew asked for the zip codes of the participants' place of residence and the modes of transportation they used to visit the market. The target was to collect the visitor metrics during four-hour periods on two market dates at every participating market to reduce event-specific effects. ${ }^{2}$ The first round of visitor metrics was collected from most, if not all, participating markets before the second round of collection took place.

Recognizing a market as a coherent unit, the team prioritized collecting all metrics from a given market over encompassing all markets in the region at the start. Thus, the metrics collection first engaged a limited number of markets and progressively expanded the geographic scope. This enabled not only reporting of impacts at any geographic identity, but also allowed for adjusting the scope by available funds. For the Farmers Market Metrics Project, the plan of scaling up has allowed for the project to begin with limited funds while additional funds were sought. The scale of the project and its participating markets has roughly doubled every season. It started with 12 predominantly Minneapolis-based markets in 2016's pilot season, increased to 27 markets in Minneapolis and St. Paul in 2017's first season of USDA funding, and finally increased to 53 markets across the MSP metro area in 2018. The project plans to reach all 90 or so metro farmers markets in 2019.

\section{Discussion}

The Farmers Market Metrics Project utilizes our FM360 approach driven by a productive, three-way partnership. The FM360 approach consists of regional-scale, market-wide (vendor, customer, and manager) scope, and minimal resource commitment from market vendors and managers. The unique characteristic of this approach is that since the methods are standardized, markets across the region can compare their results to various levels of benchmarks, making the project outputs not only informative to the assessment of the regional food system, but also valuable to farmers markets on an individual basis.

Perhaps most critical to the project's success thus far is the three-way partnership between the markets, the city, and the university that has led the endeavor. This partnership has helped the project

\footnotetext{
${ }^{1}$ Varner and Otto (2008) mention that in their study, the attendance record was inconsistent across markets because managers were asked to count and provide them.

${ }^{2}$ Market hours or weather might call for fewer hours of collection period in some cases, but for a valid set of metrics, at minimum two hours were allocated. Also, collection might occur on only one market date at the smallest markets.
} 
face the challenge of sustainability, both in terms of leadership and funding. Two managers on the project team have moved on, but the project has withstood the turnover owing in part to the steadiness of the government and university members and to the successors of the managers taking their places on the project team. The government and university partners have shared responsibility for moving the project along and contributed resources that have been complementary. Farmers market managers have provided site-level coordination that otherwise would have expended project resources.

Refining the implementation procedures is an ongoing process, and several more seasons are needed to identify best practices for the FM360 method. For example, the way we administer vendor surveys will continue to evolve to improve response rates. The project is currently supported by a three-year grant, and the future of metrics collection beyond the grant period is unknown. Several strategies and scenarios are being explored to sustain the efforts. This challenge of coming up with realistic and promising options for the financial sustainability for the future of the metrics endeavor is the key to being able to fully propose the FM360 as a new sustainable and replicable method.

\section{Conclusion}

It is critical to equip communities with tools to effectively demonstrate the importance of their food system activities before any existing funding support or momentum is lost. This research brief reports on how the Farmers Market Metrics Project is collecting metrics from three distinct stakeholders at markets in the MSP metro region. The three-way partnership among farmers markets, the local government, and university has been valuable when forming a team for planning and implementing data collection. The FM360 approach is scalable across geographic areas, which is important in cases involving multiple data sources and when flexibility is needed in defining the food system parameters to satisfy all members of the team or prospective funders.

The Farmers Market Metrics Project is yielding rich data from vendors, visitors, and market managers, which will be fully analyzed to reveal the presence of farmers markets in the MSP metro region. Such findings from metrics will be deferred until the end of the project. In 2019, the project ideally will lay the groundwork for a foundation of sustained data collection that Twin Cities farmers markets can use to better articulate their contribution to the regional food system and their respective communities. A next step is to work with communities in regions beyond the MSP metro to further examine the adaptability, scalability, and effectiveness of FM360 in different settings and locations. The team welcomes collaboration with other communities around the nation that may consider adapting the FM360 approach to benchmark capacity-building efforts for their local food systems.

\section{Acknowledgments}

The authors gratefully acknowledge Tamara Downs Schwei of Homegrown Minneapolis, Miguel Goebel and Mallory Forseth of Midtown Farmers Market, Martha Archer of Mill City Farmers Market, Pat Nelson of Minneapolis Farmers Markets, Alexandra Cortes and Emily Lund of Neighborhood Roots Farmers Markets, and DeVon Nolen of West Broadway Farmers Markets on our journey on this project thus far.

\section{References}

Brown, C., \& Miller, S. (2008). The impacts of local markets: A review of research on farmers markets and community supported agriculture (CSA). American Journal of Agricultural Economics, 90(5), 1296-1302. https://doi.org/10.1111/j.1467-8276.2008.01220.x

Experience Renewal Solutions. (2009). National farmers' market impact study 2009 report. Farmers' Markets Canada. Retrieved from https://www.unbc.ca/sites/default/files/sections/david-connell/farmersmarkets/nationalfarmersmarketimpactstudy2009.pdf

Farmers Market Coalition [FMC]. (n.d.-a). Farmers market metrics: Metrics. Retrieved May 1, 2016, from http://farmersmarketcoalition.org/programs/farmers-market-metrics/metric-selection/ 
Farmers Market Coalition [FMC]. (n.d.-b). Programs: Farmers market metrics. Retrieved March 5, 2019, from https:// farmersmarketcoalition.org/programs/farmers-market-metrics/

Henneberry, S. R., Whitacre, B., \& Agustini, H. N. (2009). An evaluation of the economic impacts of Oklahoma farmers markets. Journal of Food Distribution Research, 40(3), 64-78. http://purl.umn.edu/99760

Hughes, D. W., \& Isengildina-Massa, O. (2015). The economic impact of farmers' markets and a state level locally grown campaign. Food Policy, 54, 78-84. https://doi.org/10.1016/j.foodpol.2015.05.001

Lev, L., Brewer, L. J., \& Stephenson, G. (2008). Tools for Rapid Market Assessments (Special Report 1088-E). Retrieved from https:// catalog.extension.oregonstate.edu/sr1088

Maine Federation of Farmers' Markets. (2017). Maine Farmers' Market Annual Report 2017. Pittsfield: Maine Federation of Farmers' Markets.

Market Umbrella. (2012). Farmers markets contribute millions to local, regional economies [Press release]. Retrieved July 14, 2018, from the Market Umbrella website. [No longer online].

Nowak, J. (2019, February). Visitor count insights [Webinar session]. Presented with L. Schreiber, Farmers Market Metrics in Minnesota. Webinar hosted by Midwest Farmers Market Partners and USDA Food and Nutrition Services.

Ostrom, M., \& Donovan, C. (2013). Summary report: Farmers markets and the experiences of market managers in Washington state. Washington State University Small Farms Program. Retrieved from http://csanr.wp2.cahnrs.wsu.edu/wpcontent/uploads/sites/32/2013/11/WSU-FMMS-report-Nov-2013.pdf

Sadler, R. C., Clark, M. A. R., \& Gilliland, J. A. (2013). An economic impact comparative analysis of farmers' markets in Michigan and Ontario. Journal of Agriculture, Food Systems, and Community Development, 3(3), 61-81. https://doi.org/10.5304/jafscd.2013.033.009

Schmit, T. M., \& Gómez, M. I. (2011). Developing viable farmers markets in rural communities: An investigation of vendor performance using objective and subjective valuations. Food Policy, 36(2), 119-127. https://doi.org/10.1016/i.foodpol.2010.10.001

U.S. Department of Agriculture Agricultural Marketing Service. (n.d.). Local Food Directories: National Farmers Market Directory. Retrieved July 2018 from https://www.ams.usda.gov/local-food-directories/farmersmarkets

Varner, T., \& Otto, D. (2008). Factors affecting sales at farmers' markets: An Iowa study. Review of Agricultural Economics, 30(1), 176-189. https://doi.org/10.1111/j.1467-9353.2007.00398.x 